Designed Monomers and Polymers, Vol. 8, No. 4, pp. 287-296 (2005)

(C) VSP 2005.

Also available online - www.vsppub.com

\title{
Improved synthesis of bis(chloromethyl)arene monomers
}

\author{
MARCELA F. ALMASSIO, MYRIAN N. SARIMBALIS \\ and RAÚL O. GARAY*
}

INIQO, Departamento de Química, Universidad Nacional del Sur, Alem 1253, 8000-Bahía Blanca, Argentina

\begin{abstract}
We report here on the experimental conditions for radical chlorination that provide improved yields of 2,5-bis(chloromethyl) pyridine and pyrazine, as well as on theoretical calculations which were performed in order to gain some insight regarding the factors that affect reactivity in these systems. The difficulties encountered previously in the methyl functionalization of N-heteroarenes are not due to radical selectivity that produces low yield of the dichlorides or to lower reactivity of this type of compounds, but to the post-halogenation reactions that occur on the desired products. Therefore, a careful handling during and after the reaction allowed us to find conditions for product optimization of $\alpha, \alpha^{\prime}$-dichlorinated monomers.
\end{abstract}

Keywords: bis(Halomethyl)aryl; monomers; halogenation; product optimization; conjugated polymers.

\section{INTRODUCTION}

Our interest in bis(halomethyl)aryl compounds such as 2,5-bis(halomethyl) derivatives of benzene or nitrogenated arenes stems from their diverse use as monomers or as key intermediates in monomer syntheses for the preparation of polyconjugated polymers of the polyarylene vinylene type by the Gilch route [1] or the sulfonium salt route [2]. In particular, nitrogenated arenes are frequently incorporated in conjugated polymers in order to improve their electron affinity [3]. These dihalo monomers can be obtained starting from the dicarboxylic acid using a standard synthetic route consisting of four steps, namely oxidation of the methyl groups to the corresponding dicarboxylic acids, methylation, reduction to the diol and their final conversion to the $\alpha, \alpha^{\prime}$-dihalide [4]. However, the radical halogenation of benzyl positions offers a one-step procedure that gives good results for the bromina-

\footnotetext{
*To whom correspondence should be addressed. Fax: (54-291) 459-5187; e-mail: rgaray@criba.edu.ar
} 
tion of symmetric dimethylaryl derivatives such as dimethylnaphtalene [5]. Nevertheless, the high selectivity of the radical bromination usually makes the procedure cumbersome when both methyl group reactivities differ due to steric or electronic effects. Thus, the bromination of 2-cyano-5-methoxy- $p$-xylene gave substantial amounts of the asymmetric $\alpha, \alpha$-brominated product, 2-cyano-5-methoxy4-(dibromomethyl)toluene, along with the desired 1,4-bis(bromomethyl)-2-cyano5-methoxybenzene [6]. On the other hand, it is well known that radical chlorination is less selective than bromination. Therefore, N-chlorosuccinimide (NCS) radical chlorination could offer acceptable results in cases such as the chlorination of 2,5-lutidine, where a difference in reactivity between both methyl groups is to be expected. However, although the radical halogenation of arenes using $\mathrm{N}$-bromosuccinimide is a frequently used procedure for methyl functionalization, the radical chlorination is less common. In particular, methyl group halogenation in heterocyclic systems using NCS as the chlorine source has been the subject of only a few literature reports [7-10], in which low yields and instability of products are commonplace. In addition, the reaction product usually consists in mixtures of mono-, di- and even polychlorinated compounds from which the desired dichloride is not easy to isolate. We report here a study of the radical chlorination of 2,5-dimethylbenzene, 2,5-dimethylpyridine and 2,5-dimethylpyrazine that allowed us to find experimental conditions that provide improved yields of the bis(halomethyl)aryl compounds. The by-products were identified and characterized by NMR spectroscopy. Moreover, theoretical calculations were performed in order to gain some insight regarding the factors that affect reactivity in these systems.

\section{MATERIALS AND METHODS}

Melting points reported are not corrected. Elemental analyses were made in the Universidad de Buenos Aires, INQUIMAE. ${ }^{1} \mathrm{H}-\mathrm{NMR}$ and ${ }^{13} \mathrm{C}-\mathrm{NMR}$ spectra were recorded on a Bruker $\mathrm{ARX} 300$ spectrometer using $\mathrm{CDCl}_{3}$ dried over molecular sieves. For spectra using $\mathrm{CCl}_{4}$ as a solvent, $\mathrm{D}_{2} \mathrm{O}$ in a concentric inner tube was used as lock standard. UV irradiation experiments were conducted under illumination from a $60-\mathrm{W}$ Hanau mercury lamp. Benzoyl peroxide was recrystallized twice from ethanol. Tetrachloromethane and chlorobenzene were distilled and kept over molecular sieves. para-Xylene with both methyl groups having $>98 \%{ }^{13} \mathrm{C}$ label was obtained from Isotec (Cambridge, MA, USA).

\subsection{Syntheses of the dichlorides}

2.1.1. 2,5-Bis(chloro- ${ }^{13} \mathrm{C}$-methyl)benzene (2a). Either para-xylene for the trial tests or para-xylene- $\alpha, \alpha^{\prime}$-di- ${ }^{13} \mathrm{C}(1.0 \mathrm{~g}, 9.2 \mathrm{mmol})$ for the final run and finely divided N-chlorosuccinimide (NCS, $3.56 \mathrm{~g}, 28 \mathrm{mmol}$ ) were mixed in $7 \mathrm{ml}$ clorobenzene and heated at $130^{\circ} \mathrm{C}$ for $2 \mathrm{~h}$, while the mixture was irradiated with a UV lamp. Then the solvent was distilled and the remaining solid was extracted with hot $\mathrm{CCl}_{4}$ 
$(4 \times 10 \mathrm{ml})$. The solid was recrystallized in cyclohexane. M.p. $97-99^{\circ} \mathrm{C}$ (lit. 99$101^{\circ} \mathrm{C}$ for the material with normal isotopic abundance).

2.1.2. 2,5-Bis(chloromethyl)pyridine (2b). Two portions of dibenzoylperoxide (BPO) were added to a stirred suspension of 2,5-dimethylpyridine (1.6 g, $15 \mathrm{mmol})$ and finely divided NCS $(5.01 \mathrm{~g}, 38 \mathrm{mmol})$ in $60 \mathrm{ml}$ of boiling tetrachloromethane. One portion of BPO $(0.1 \mathrm{~g})$ was added at the beginning of the reaction and a second one $(0.05 \mathrm{~g})$ was added after $4 \mathrm{~h}$. The stirred mixture was heated under nitrogen at reflux temperature for $24 \mathrm{~h}$, and after cooling to $0-5^{\circ} \mathrm{C}$ the precipitated succinimide was filtered off and washed with tetrachloromethane. The combined filtrates were stored at $0^{\circ} \mathrm{C}$ and then concentrated under reduced pressure immediately before chromatographic purification. The rotary evaporator bath temperature was maintained at $40^{\circ} \mathrm{C}$ during all work-up procedures. Chromatography of the oily residue (silicagel; eluent: first dichloromethane/hexane (2:1), then dichloromethane) yielded first a mixture of $\mathbf{3 b}$ and $\mathbf{3}^{\prime} \mathbf{b}$, and then $\mathbf{2 b}(48 \%)$ as a colorless oil. $\mathbf{2 b}$ was dissolved in tetrachlomethane $(20 \mathrm{ml})$ and stored at $4^{\circ} \mathrm{C}$. A small portion of the oil was set aside and it crystallized after standing overnight at $-14^{\circ} \mathrm{C}$. M.p. $43-44^{\circ} \mathrm{C}$ (lit. [9] $44-46^{\circ} \mathrm{C}$ ).

2.1.3. 2,5-Bis(chloromethyl)-pyrazine (2c). 2,5-Dimethylpyrazine (2.1 g, 19 $\mathrm{mmol})$, NCS (6.41 g, $48 \mathrm{mmol})$ and BPO (0.12 and $0.06 \mathrm{~g})$ in $70 \mathrm{ml}$ anhydrous tetrachloromethane were treated as described above. Chromatographic purification (eluent: dichloromethane) first afforded $\mathbf{3 c / 4 c}$ mixtures, then $\mathbf{4 c / 2} \mathbf{c}$ mixtures and finally $\mathbf{2 c}(55 \%)$ as a colorless oil. $\mathbf{2 c}$ was dissolved in tetrachloromethane $(20 \mathrm{ml})$ and stored at $4^{\circ} \mathrm{C}$. A small portion of the oil was recrystallized in hexane at $4{ }^{\circ} \mathrm{C}$. M.p. $67-68^{\circ}$ C. Anal. calcd. for $\mathrm{C}_{6} \mathrm{H}_{6} \mathrm{Cl}_{2} \mathrm{~N}_{2}$ : C, 40.71; H, 3.42; Cl, 40.05; N, 15.82 . Found: C, 40.31; H, 3.89; N, 15.57.

\subsection{Benzylic proton reactivities studies}

Aliquots were periodically withdrawn from the reaction mixture, filtered through cotton and then analyzed by NMR spectroscopy. In order to carry out the analyses, and since only the dichlorides $\mathbf{2 a}, \mathbf{2} \mathbf{b}$ and $\mathbf{2 c}$ were obtained in a pure form, all the ${ }^{1} \mathrm{H}$ - and ${ }^{13} \mathrm{C}-\mathrm{NMR}$ signals for the rest of the di- and trichlorinated products were assigned from NMR data obtained from mixtures containing variable amounts of these byproducts and confirmed with the help of 2D NMR experiments. The following numbering system to describe the proton and carbons in the range of structurally similar compounds was applied to the ${ }^{1} \mathrm{H}$ - and ${ }^{13} \mathrm{C}-\mathrm{NMR}$ spectra (Scheme 1).

2.2.1. $\alpha, \alpha^{\prime}$-Dichloride- $\alpha, \alpha^{\prime}-{ }^{13} C(2 a) . \quad{ }^{1} \mathrm{H}-\mathrm{NMR}: \delta 4.56\left(\mathrm{~d}, 4 \mathrm{H}^{1,2},{ }^{1} J_{\mathrm{C}-\mathrm{H}} 150.9\right.$ $\mathrm{Hz}), 7.34-7.41\left(4 \mathrm{H}^{4,5,7,8}\right) .{ }^{13} \mathrm{C}-\mathrm{NMR}: \delta 45.9\left(\mathrm{C}^{1,2}\right), 128.9\left(\mathrm{C}^{4,5,7,8}\right), 138.0\left(\mathrm{C}^{3,6}\right)$. 


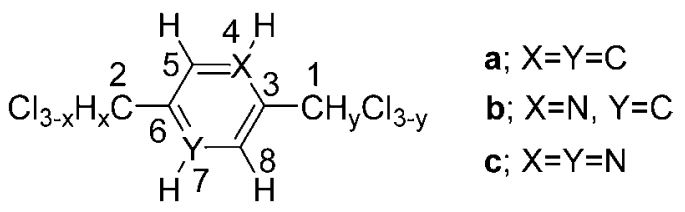

\section{Scheme 1.}

2.2.2. $\alpha, \alpha, \alpha^{\prime}$-Trichloride- $\alpha, \alpha^{\prime}-{ }^{13} C(3 a) . \quad{ }^{1} \mathrm{H}-\mathrm{NMR}: \delta 4.57\left(\mathrm{~d}, 2 \mathrm{H}^{2},{ }^{1} J_{\mathrm{C}-\mathrm{H}} 151.1\right.$ $\mathrm{Hz}), 6.69\left(\mathrm{~d}, 1 \mathrm{H}^{1},{ }^{1} J_{\mathrm{C}-\mathrm{H}} 178.3 \mathrm{~Hz}\right), 7.40-7.46\left(2 \mathrm{H}^{5,7}\right), 7.51-7.59\left(2 \mathrm{H}^{4,8}\right) .{ }^{13} \mathrm{C}-$ NMR: $\delta 45.3\left(\mathrm{C}^{2}\right), 71.2\left(\mathrm{C}^{1}\right)$.

2.2.3. $\alpha, \alpha$-Dichloride- $\alpha, \alpha^{\prime}-{ }^{13} \mathrm{C}(\mathbf{4 a}) . \quad{ }^{1} \mathrm{H}-\mathrm{NMR}: \delta 2.36\left(\mathrm{~d}, 3 \mathrm{H}^{2},{ }^{1} J_{\mathrm{C}-\mathrm{H}} 126.8 \mathrm{~Hz}\right)$, $6.68\left(\mathrm{~d}, 1 \mathrm{H}^{1},{ }^{1} J_{\mathrm{C}-\mathrm{H}} 178.1 \mathrm{~Hz}\right), 7.40-7.46\left(2 \mathrm{H}^{5,7}\right), 7.51-7.59\left(2 \mathrm{H}^{4,8}\right) .{ }^{13} \mathrm{C}-\mathrm{NMR}$ : $\delta 21.22\left(\mathrm{C}^{2}\right), 71.8\left(\mathrm{C}^{1}\right)$.

2.2.4. $\alpha$-Monochloride- $\alpha, \alpha^{\prime}-{ }^{13} \mathrm{C}(5 \boldsymbol{a}) . \quad{ }^{1} \mathrm{H}-\mathrm{NMR}: \delta 2.34\left(\mathrm{~d}, 3 \mathrm{H}^{2},{ }^{1} J_{\mathrm{C}-\mathrm{H}} 126.5\right.$ $\mathrm{Hz}), 4.55\left(\mathrm{~d}, 2 \mathrm{H}^{1},{ }^{1} J_{\mathrm{C}-\mathrm{H}} 150.9 \mathrm{~Hz}\right), 7.11-7.19\left(2 \mathrm{H}^{5,7}\right), 7.25-7.30\left(2 \mathrm{H}^{4,8}\right) .{ }^{13} \mathrm{C}-$ NMR: $\delta 21.17\left(\mathrm{C}^{2}\right), 46.8\left(\mathrm{C}^{1}\right)$.

2.2.5. $\alpha, \alpha^{\prime}$-Dichloride (2b). ${ }^{1} \mathrm{H}$-NMR: $\delta 4.58\left(\mathrm{~s}, 2 \mathrm{H}^{2}\right), 4.67\left(\mathrm{~s}, 2 \mathrm{H}^{1}\right), 7.49(\mathrm{~d}$, $\left.1 \mathrm{H}^{8}, J_{\mathrm{o}} 8.0 \mathrm{~Hz}\right), 7.78\left(\mathrm{dd}, 1 \mathrm{H}^{7}, J_{\mathrm{o}} 8.0 \mathrm{~Hz}, J_{\mathrm{m}} 2.3 \mathrm{~Hz}\right), 8.56\left(\mathrm{~d}, 1 \mathrm{H}^{5}, J_{\mathrm{m}} 2.3 \mathrm{~Hz}\right)$. ${ }^{13}$ C-NMR: $\delta 42.6\left(C^{2}\right), 45.9\left(C^{1}\right), 122.9\left(C^{8}\right), 132.9\left(C^{6}\right), 137.7\left(C^{7}\right), 148.7\left(C^{5}\right)$, $156.5\left(C^{3}\right)$.

2.2.6. $\alpha, \alpha, \alpha^{\prime}$-Trichloride (3b). ${ }^{1} \mathrm{H}-\mathrm{NMR}$ : $\delta 4.59\left(\mathrm{~s}, 2 \mathrm{H}^{2}\right), 6.72\left(\mathrm{~s}, 1 \mathrm{H}^{1}\right), 7.78(\mathrm{~d}$, $\left.1 \mathrm{H}^{8}, J_{\mathrm{o}} 7.9 \mathrm{~Hz}\right), 7.86\left(\mathrm{dd}, 1 \mathrm{H}^{7}, J_{\mathrm{o}} 7.9 \mathrm{~Hz}, J_{\mathrm{m}} 2.0 \mathrm{~Hz}\right), 8.56\left(\mathrm{~d}, 1 \mathrm{H}^{5}, J_{\mathrm{m}} 2.0 \mathrm{~Hz}\right)$. ${ }^{13}$ C-NMR: $\delta 42.4\left(C^{2}\right), 71.0\left(C^{1}\right), 121.1\left(C^{8}\right), 134.1\left(C^{6}\right), 137.9\left(C^{7}\right), 148.4\left(C^{5}\right)$, $157.9\left(C^{3}\right)$.

2.2.7. $\alpha, \alpha, \alpha^{\prime}$-Trichloride (3'b). ${ }^{1} \mathrm{H}-\mathrm{NMR}: \delta 4.68\left(\mathrm{~s}, 2 \mathrm{H}^{1}\right), 6.74\left(\mathrm{~s}, 1 \mathrm{H}^{2}\right), 7.56$ $\left(\mathrm{d}, 1 \mathrm{H}^{8}, J_{\mathrm{o}} 8.2 \mathrm{~Hz}\right), 8.00\left(\mathrm{dd}, 1 \mathrm{H}^{7}, J_{\mathrm{o}} 8.2, J_{\mathrm{m}} 2.5 \mathrm{~Hz}\right), 8.68\left(\mathrm{~d}, 1 \mathrm{H}^{5}, J_{\mathrm{m}} 2.5 \mathrm{~Hz}\right)$. ${ }^{13} \mathrm{C}-\mathrm{NMR}$ : $\delta 46.0\left(\mathrm{C}^{1}\right), 68.7\left(\mathrm{C}^{2}\right), 122.8\left(\mathrm{C}^{8}\right), 135.3\left(\mathrm{C}^{7}\right), 135.6\left(\mathrm{C}^{6}\right), 146.5\left(\mathrm{C}^{5}\right)$, $158.2\left(\mathrm{C}^{3}\right)$.

2.2.8. $\alpha, \alpha^{\prime}$-Dichloride (2c). ${ }^{1} \mathrm{H}-\mathrm{NMR}: \delta 4.71\left(\mathrm{~s}, 4 \mathrm{H}^{1,2}\right), 8.71\left(\mathrm{~s}, 2 \mathrm{H}^{5,8}\right) .{ }^{13} \mathrm{C}$ NMR: $\delta 43.6\left(\mathrm{C}^{1,2}\right), 143.5\left(\mathrm{C}^{5,8}\right), 151.5\left(\mathrm{C}^{2,6}\right)$.

2.2.9. $\alpha, \alpha, \alpha^{\prime}$-Trichloride (3c). ${ }^{1} \mathrm{H}-\mathrm{NMR}$ : $\delta 4.72\left(\mathrm{~s}, 2 \mathrm{H}^{2}\right), 6.80\left(\mathrm{~s}, 1 \mathrm{H}^{1}\right), 8.71(\mathrm{~s}$, $\left.1 \mathrm{H}^{5}\right), 8.98\left(\mathrm{~s}, 1 \mathrm{H}^{8}\right) .{ }^{13} \mathrm{C}-\mathrm{NMR}: \delta 43.4\left(\mathrm{C}^{2}\right), 68.8\left(\mathrm{C}^{1}\right), 142.0\left(\mathrm{C}^{8}\right), 142.6\left(\mathrm{C}^{5}\right), 152.4$ $\left(\mathrm{C}^{6}\right), 154.9\left(\mathrm{C}^{3}\right)$.

2.2.10. $\alpha, \alpha$-Dichloride (4c). $\quad{ }^{1} \mathrm{H}-\mathrm{NMR}: \delta 2.63\left(\mathrm{~s}, 3 \mathrm{H}^{2}\right), 6.77\left(\mathrm{~s}, 1 \mathrm{H}^{1}\right), 8.44(\mathrm{~s}$, $\left.1 \mathrm{H}^{5}\right), 8.88\left(\mathrm{~s}, 1 \mathrm{H}^{8}\right) .{ }^{13} \mathrm{C}-\mathrm{NMR}$ : $\delta 21.4\left(\mathrm{C}^{2}\right), 69.1\left(\mathrm{C}^{1}\right), 141.5\left(\mathrm{C}^{8}\right), 143.1\left(\mathrm{C}^{5}\right), 150.2$ $\left(\mathrm{C}^{6}\right), 152.8\left(\mathrm{C}^{3}\right)$. 
2.2.11. $\alpha$-Monochloride (5c). ${ }^{1} \mathrm{H}-\mathrm{NMR}: \delta 2.59\left(\mathrm{~s}, 3 \mathrm{H}^{2}\right), 4.67\left(\mathrm{~s}, 2 \mathrm{H}^{1}\right), 8.44(\mathrm{~s}$, $\left.1 \mathrm{H}^{5}\right), 8.61\left(\mathrm{~s}, 1 \mathrm{H}^{8}\right) .{ }^{13} \mathrm{C}-\mathrm{NMR}: \delta 21.3\left(\mathrm{C}^{2}\right), 43.9\left(\mathrm{C}^{1}\right), 143.3\left(\mathrm{C}^{5}\right), 143.9\left(\mathrm{C}^{8}\right), 149.0$ $\left(\mathrm{C}^{6}\right), 153.5\left(\mathrm{C}^{3}\right)$.

\subsection{Molecular modeling}

Molecular modeling was performed by first using the $6-31 \mathrm{G}^{*}$ program to model geometries and then using the $6-31 \mathrm{G}^{* *}$ program to calculate electronic densities [13]. The minimization operations for close shell molecules (RHF) were performed using the conjugate gradient method where minimization was halted by setting the gradient option at $0.01 \mathrm{kcal} /$ Åmol. Then, a vibrational spectrum calculation was performed on each of the minimized structures. A local minimum and not at saddle point was assigned to the molecular structure when the spectrum showed only positive vibrational modes.

\section{RESULTS AND DISSCUSION}

In principle, we were interested in 1,4-bis(chloro- ${ }^{13} \mathrm{C}$-methyl)benzene, which could be used for assaying blockiness in conjugated co-polymers through ${ }^{13} \mathrm{C}-{ }^{13} \mathrm{C}-\mathrm{NMR}$ coupling [11]. In this case, the shortest synthetic route is the radical chlorination of ${ }^{13} \mathrm{C}$-labeled $p$-xylene. Therefore, we perform first a series of experiments with the non-labeled $p$-xylene, 1a, in order to find the best conditions for benzylic chlorination. Table 1 shows that in this case high temperature and UV irradiation gave the fastest reactions and higher yields of $\mathbf{2 a}$, although it was obtained along with trichloride 3a, the dichloride $\mathbf{4 a}$ and traces of the monochloride $\mathbf{5 a}$. We then tried this procedure with nitrogen-containing compounds. Regrettably, under these conditions $\mathbf{1 b}$ as well as $\mathbf{1 c}$ gave only viscous dark oils that showed complex ${ }^{1} \mathrm{H}$ NMR spectra and were rather soluble in protic solvents, including water. Most probably, these oils were mixtures of oligomeric pyridinium or pyrazinium salts resulting from self-condensation of the chlorinated products. Since the reaction conditions at elevated temperature employed for $p$-xylene could not be used, we performed the chlorination of the nitrogen-containing compounds at the reflux temperature of tetrachloromethane using benzoyl peroxide as the radical initiator instead. Although comparable standard conditions have been used for methyl chlorination of $\mathbf{1 b}$ and $\mathbf{1 c}$ previously, the reported yields for the dichloride $\mathbf{2} \mathbf{b}$ were $20 \%$ [7], 23\% [8] and 29\% [9] while in the case of $\mathbf{1 c}$ the reaction afforded $70 \%$ yield of the monochloride $\mathbf{5 c}$ [10].

We found that both $\mathbf{1 b}$ and $\mathbf{1 c}$ afforded the desired dichlorides along with variable amounts of monochlorinated, isomeric dichlorides and trichlorinated compounds (see Fig. 1). In order to find the best reaction conditions we followed the chlorination reactions by ${ }^{1} \mathrm{H}-\mathrm{NMR}$ spectroscopy. The ${ }^{1} \mathrm{H}-\mathrm{NMR}$ analysis of aliquots which were withdrawn from the reaction mixture of dimethylpyridine, $\mathbf{1 b}$, indicated that a substantial amount of the methyl groups (ca. 70\%) reacted after $4 \mathrm{~h}$ while 
Table 1.

Reaction conditions and results for the radical chlorination with NCS

\begin{tabular}{|c|c|c|c|c|c|c|}
\hline Substrate & $\begin{array}{l}\text { Substrate/NCS } \\
\text { ratio }(\mathrm{mol} / \mathrm{mol})\end{array}$ & Initiator & Solvent & $\begin{array}{l}\text { Bath } \\
\text { temperature } \\
\left({ }^{\circ} \mathrm{C}\right)\end{array}$ & $t(\mathrm{~h})$ & Yield \\
\hline & $1: 3$ & $\mathrm{BPO}$ & $\mathrm{PhCl}$ & 115 & 0.2 & 70 \\
\hline & $1: 3$ & $\mathrm{BPO}$ & $\mathrm{PhCl}$ & 115 & 3.0 & 78 \\
\hline & $1: 2$ & UV light & $\mathrm{PhCl}$ & 130 & 0.2 & 70 \\
\hline & $1: 3$ & UV light & $\mathrm{PhCl}$ & 130 & 2.0 & 86 \\
\hline & $1: 3$ & UV light & $\mathrm{PhCl}$ & 120 & 2.0 & Decomposed \\
\hline & $1: 2.2$ & $\mathrm{BPO}$ & $\mathrm{CCl}_{4}$ & 77 & 24 & 46 \\
\hline & $1: 2.5$ & $\mathrm{BPO}$ & $\mathrm{CCl}_{4}$ & 85 & 24 & 54 \\
\hline & $1: 2.5$ & $\mathrm{BPO}$ & $\mathrm{CCl}_{4}$ & 85 & 24 & 68 \\
\hline
\end{tabular}

Yield is percentage of $\alpha, \alpha^{\prime}$-dichlorinated product, as measured by ${ }^{1} \mathrm{H}-\mathrm{NMR}$.

most of them (>97\%) had at least one hydrogen substituted after $24 \mathrm{~h}$. However, an equimolar mixture of the two $\alpha, \alpha, \alpha^{\prime}$-trichlorides $\mathbf{3 b}$ and $\mathbf{3}^{\prime} \mathbf{b}$ (46\% yield based on the ${ }^{1} \mathrm{H}$-NMR spectra) was also formed along with the $\alpha, \alpha^{\prime}$-dichloride $\mathbf{2 b}$ (54\% yield). Also, the ${ }^{1} \mathrm{H}-\mathrm{NMR}$ spectra of aliquots withdrawn from reaction mixtures of $\mathbf{1 b}$ showed two signals in $1: 1$ ratio at 6.28 and $6.20 \mathrm{ppm}$ that we assigned to the $\mathrm{CHCl}_{2}$ groups belonging to the trichlorides $\mathbf{3 b}$ and $\mathbf{3}^{\prime} \mathbf{b}$ (see Fig. 1). The first fractions of the chromatographic purification afforded a mixture of both trichlorides, which could be easily, separated ( $c a$. 35\% isolated yield) from $\mathbf{2 b}$. But instead attempts to decrease 2a trichlorination using shorter reaction times or lower NCS/substrate ratios yielded variable amounts of the monochlorinated products $\mathbf{5 b}$ and $\mathbf{5}^{\prime} \mathbf{b}$ whose separation from $\mathbf{2} \mathbf{b}$ was very difficult. On the other hand, longer reaction times and/or higher NCS/substrate ratios only led to an increase in the amount of the trichlorides as expected, e.g., $60 \%$ after $48 \mathrm{~h}$ using a 1:3 NCS/substrate ratio. Likewise, the ${ }^{1} \mathrm{H}-\mathrm{NMR}$ analysis of the reaction mixture showed that chlorination of dimethylpyrazine, 1c, afforded the desired $\alpha, \alpha^{\prime}$-dichloride 2c (64\% yield) along with $\alpha, \alpha$-dichloride $4 \mathbf{c}$ (9\% yield) and the $\alpha, \alpha, \alpha^{\prime}$-trichloride $3 \mathbf{c}$ (27\% yield). Here, the presence of small amounts the $\alpha, \alpha$ dichloride $4 \mathbf{c}$ made the isolation of $\alpha, \alpha^{\prime}$-dichloride $2 \mathbf{c}$ more difficult. Once more, the use of lower NCS/substrate ratios led to more complex mixtures that included the monochlorinated compound $\mathbf{5 c}$. 

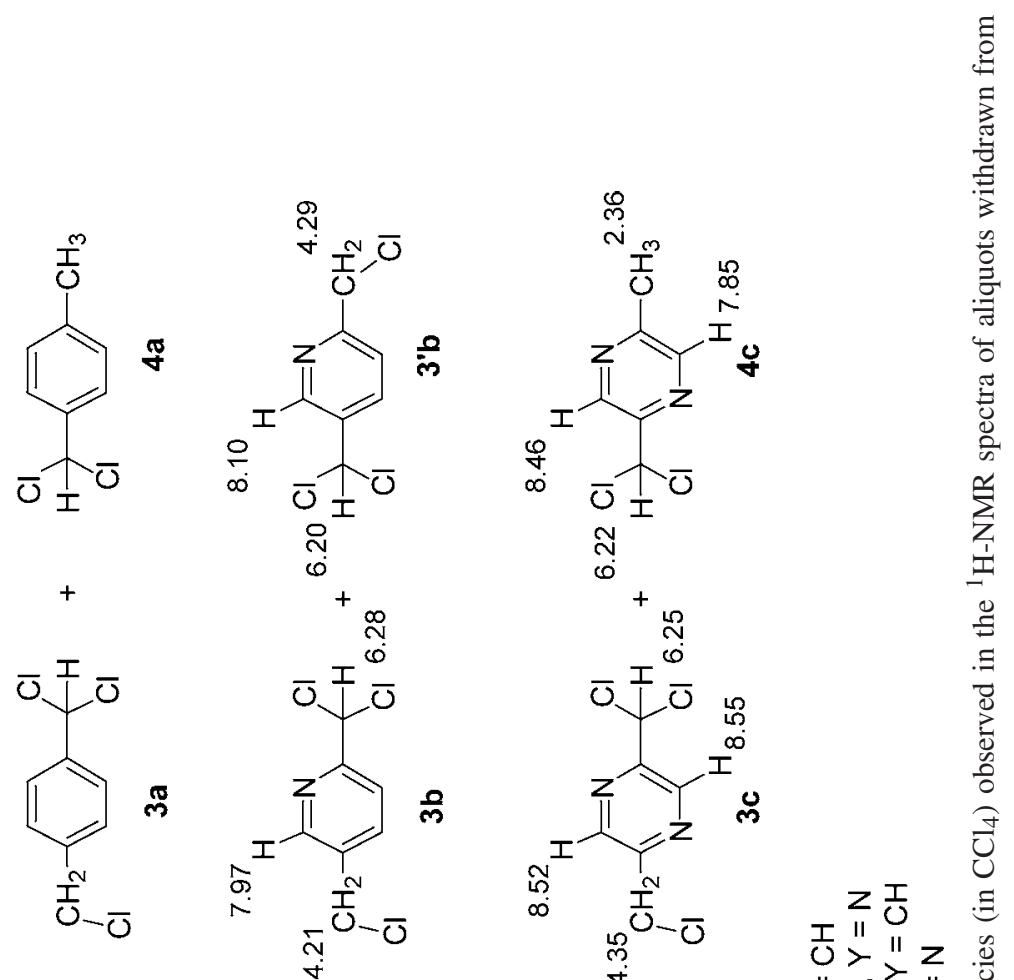<smiles>OC[OH2+]</smiles>

กี<smiles>O=Cc1ccccc1</smiles><smiles>[O]Cc1ccc(C=[Ge])c(C=O)c1</smiles>

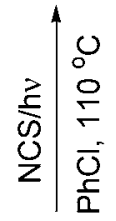
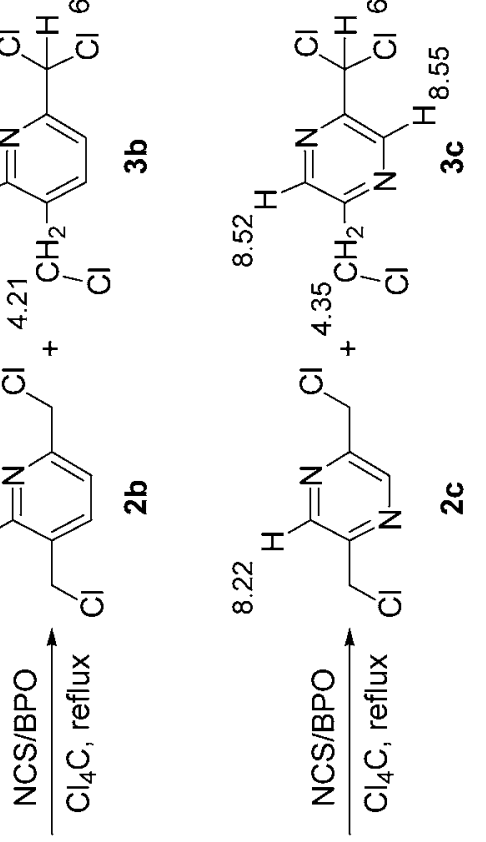

$Z I$
$I I I$
$U>I I Z$
II $>$
$>U Z>$

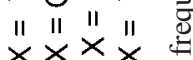<smiles>[O]c1ccc(Oc2ccccc2)cc1</smiles>
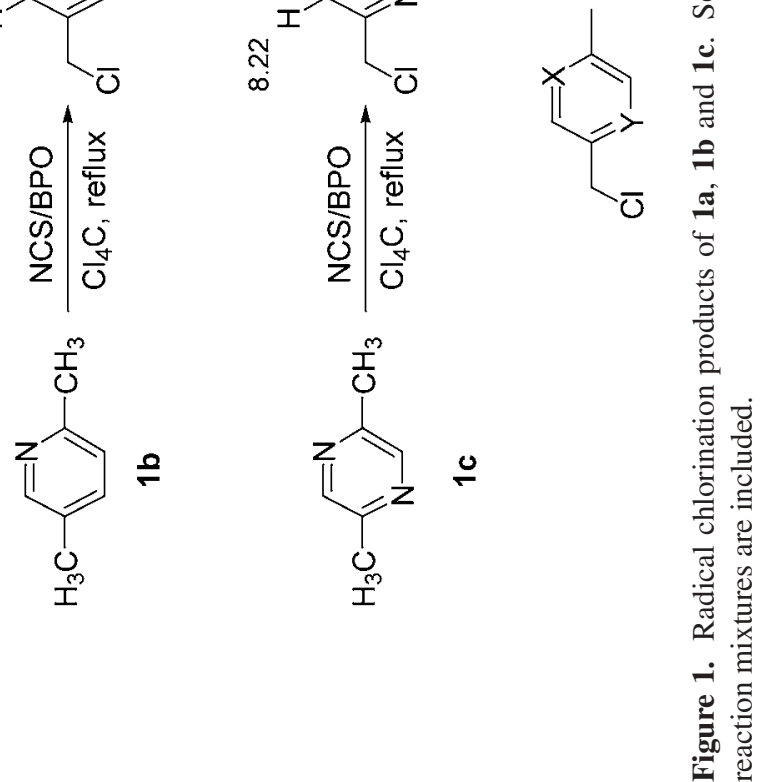


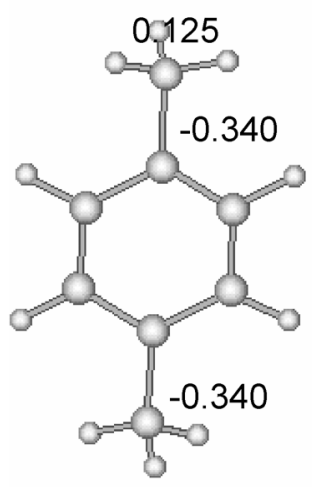

0.125

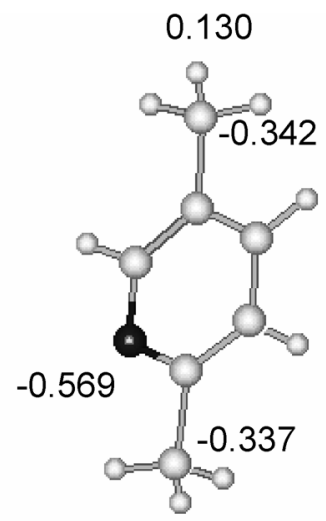

0.131

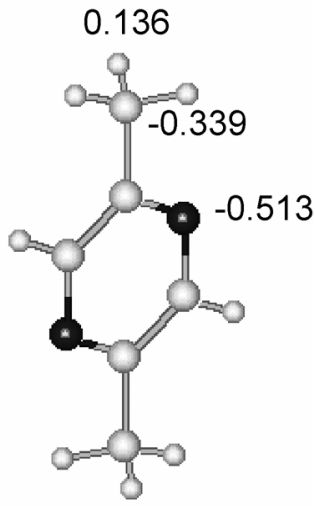

Figure 2. Calculated net charges on atoms of arenes: (a) 1a, (b) $\mathbf{1 b}$ and (c) 1c.

Thus, by adjusting the reaction conditions we were able to obtain isolated yields after chromatographic purification of $45-48 \%$ and $50-55 \%$ for $\mathbf{2 b}$ and $\mathbf{2 c}$, respectively. We also found that the nitrogenated dichlorides are particularly stable in solutions of solvents with low polarity. It must be noted that careful handling of the reaction mixtures and products always at or near room temperature was critical. Equally important, the non-polar solvent must be removed only prior to purification or subsequent use in a reaction. Otherwise, they were handled and stored in solution. Conceivably, these non-polar solvents retard the substitution reactions at the benzylic positions that produce ionic products. Indeed, solutions of the dichlorides in $\mathrm{CCl}_{4}$ kept at $4^{\circ} \mathrm{C}$ were stable for weeks, but removal of the solvent led to dark polymeric materials after the dichlorides were left standing on a bench for a few hours or at $4^{\circ} \mathrm{C}$ for a few days.

We also noted that the ${ }^{1} \mathrm{H}-\mathrm{NMR}$ spectra of aliquots withdrawn at early stages of the halogenation revealed that both signals of the two methyl groups of $\mathbf{1 b}$ decrease at almost the same rate. Moreover, as mentioned before, the two $\mathrm{CHCl}_{2}$ signals corresponding to both trichlorides $\mathbf{3 b}$ and $\mathbf{3}^{\prime} \mathbf{b}$ have identical intensities. This behavior indicated a lack of selectivity in the halogenation of either methyl or methylene groups, despite the fact that chlorine atoms are electrophilic radicals and that the electronegative nitrogen atoms have a deactivating effect on adjacent positions in radical halogenations because they decrease hydrogen atom electron densities [12].

As a matter of fact, the experimental observations were supported by computer modeling studies of substrates $\mathbf{1 a}, \mathbf{1 b}$ and $\mathbf{1 c}$ and their monochlorides done on geometries minimized at the $a b$ initio quantum mechanical level. Thus, after singlepoint $6-31 \mathrm{G}^{* *}$ calculations on the minimized $6-31 \mathrm{G}^{*}$ geometries of $\mathbf{1 a}, \mathbf{1 b}$ and $\mathbf{1 c}$, no substantial differences were found between the average partial positive charges on the hydrogen atoms of the methyl groups, which indicate the extent of the electronic populations decrement (Fig. 2). Moreover, the electronic populations of hydrogen atoms on both methyl groups in $\mathbf{1 b}$ were rather similar. Thus, it 
can be seen in Fig. 2 that the average partial charges in the benzylic hydrogen atoms in molecules with none, one and two nitrogen atoms in the aromatic ring are slightly incremented from 0.125 to 0.130 , and then to 0.136 . These results indicate that the nitrogen substitution bears little effect on the aforementioned electronic populations and, consequently, on the hydrogen atom relative reactivities due to chlorine kinetic selectivity. On the other hand, the chlorine substitution should decrease the electronic density at the remaining hydrogen atoms attached to the substituted benzylic carbon, therefore, making subsequent substitutions in that carbon atom more difficult to occur. We observed this to be the case. For example, the monochlorinated product $\mathbf{5 c}$ can be subsequently substituted at the methyl group to give the desired $\alpha, \alpha^{\prime}$-dichloride $2 \mathrm{c}$ or at the methylene group to give the $\alpha, \alpha$-dichloride $4 \mathbf{c}$. Though the methyl chlorination is preferred on statistical grounds over the methylene chlorination on only a 1.5:1 ratio, we observe that the actual ratio of $\mathbf{2} \mathbf{c} / \mathbf{4} \mathbf{c}$ in the mixture at earlier stages of the reaction was $c a$. 5:1. Similarly, the $\mathbf{2 a} / \mathbf{4} \mathbf{c}$ ratio in the reaction mixture was $c a$. 6:1. Accordingly, the calculated average partial charge for $\mathbf{5 c}$ on the benzylic hydrogen at the methyl carbon is 0.141 , while at the methylene carbon it is 0.190 . The calculated values at similar positions in 5a are 0.130 and 0.176 . Thus, the substitution is faster at the methyl carbon due to both statistical and electronic factors. Therefore, this reaction should be successful with more structurally complex compounds if attention is paid to avoid excessive trichlorination and, in case of nitrogen containing monomers, post-halogenation reactions.

In conclusion, the difficulties encountered previously in the methyl functionalization of N-heteroarenes by chlorine substitution are not due to radical selectivity that produces low yield of the dichlorides or to a lower reactivity of the nitrogenated compounds in comparison with the one displayed by $p$-xylene. Instead, the difficulties are due to post-halogenation reactions that occur in polar media at or above room temperature. In addition, these chlorination reactions always produce mixtures of reaction products whose nature can lead to an easier separation in certain cases. Thus, it is easier to isolate the desired dichlorides from the trichlorides than from the monochlorides or the structurally isomeric $\alpha, \alpha$-dichlorides. Therefore, a careful handling during and after the reaction allowed product optimization of $\alpha, \alpha^{\prime}$ dichlorinated monomers.

\section{ACKNOWLEDGEMENTS}

Financial support for this research was provided by ANPCyT and SGCyT-UNS. M. F. A. thanks CONICET for a fellowship. M. N. S. thanks CIC for a fellowship.

\section{REFERENCES}

1. B. R. Hsieh, W. C. Wang, Y. Yu, Y. Gao, T. E. Goodwin, S. A. Gonzalez and W. A. Feld, Macromolecules 31, 631 (1998). 
2. A. Kraft, A. C. Grimsdale and A. B. Holmes, Angew. Chem. Int. Edn. 37, 402 (1998).

3. Y. Z. Wang and A. J. Epstein, Acc. Chem. Res. 32, 217 (1999).

4. R. O. Garay, H. Naarmann and K. Müllen, Macromolecules 27, 1922 (1994).

5. R. O. Garay, M. N. Sarimbalis, R. S. Montani and S. A. Hernandez, Designed Monomers Polymers 3, 231 (2000).

6. P. M. Lahti, A. Sarker, R. O. Garay, R. W. Lenz and F. E. Karasz, Polymer 35, 1312 (1994).

7. X.-C. Li, F. Cacialli, R. Cervini, A. B. Holmes, S. C. Moratti, A. C. Grimsdale and R. H. Friend, Synth. Met. 84, 159 (1997).

8. S. Gillissen, M. Jonforsen, E. Kesters, T. Johansson, M. Theander, M. R. Andersson, O. Inganäs, L. Lutsen and D. Vanderzande, Macromolecules 34, 7294 (2001).

9. G. R. Newkome, G. E. Kiefer, Y.-J. Xia and V. Gupta, Synthesis, 676 (1984).

10. A. Hirschberg and P. E. Spoerri, J. Org. Chem. 26, 2356 (1961).

11. J. A. Sanborn and P. M. Lathi, Designed Monomers Polymers 3, 245 (2000).

12. G. A. Russell, in: Free Radicals, J. K. Kochi (Ed.), Vol. 1, Chapter 7. Wiley, New York, NY (1973).

13. Hypercube, HyperChem Release 7.03. Hypercube, Gainesville, FL (2000). 